\title{
Evaluation of the productivity of the Corn (Zea mays L.) under Organic soil conditioners and mineral in the town of Mbandaka, Democratic Republic of Congo
}

\section{BOBOTO NYABOLONDO B. ${ }^{1}$, MATONDO FALANGA $\mathbf{J}^{2}$, ESUKU MOKONDO I ${ }^{1}$, BOFENDA BONYENA $^{3}$, LAMBO KONGBA ${ }^{3}$, NDUNGU BOMPOMA $C^{3}$}

\author{
${ }^{1}$ Department of National Forestry Commission, Higher institute of Fishing of Mbandaka, \\ ${ }^{2}$ Department of Biology-Chemistry, Chemistry-Physics \& Geography and Management of the Environment, \\ Teaching Higher Institute Mbandaka \\ ${ }^{3}$ Department of Agronomic and Veterinary Sciences, Teaching Higher Institute Mbandaka \\ Democratic Republic of Congo
}

\begin{abstract}
This study aims to evaluate the effect of Entada abyssinica and Tithonia diversifolia hidden on the ground compared to the NPK (17-17-17), only and in organomineral combination on the growth and the yield corn.

The treatments, in three repetitions, consisted of a witness (TO), of five levels of fertilizer contribution: biomasses of E. abyssinica and $T$. diversifolia, NPK, E. abyssinica $+N P K$ and $T$ diversifolia $+N P K$. The observations had related to the parameters of growth and production. The results obtained inform that the corn answered positively in the phase of growth under effect of fertilizer indistinctly of their nature $(p<0.05)$ compared to the witness. The highest height was observed on the treatment E. abyssinica $+N P K$ with $180 \mathrm{~cm}$ against the pilot treatment with $123.33 \mathrm{~cm}$. The diameter with the collet followed the same tendency with E abyssinica $(2.20 \mathrm{~cm})$ against $1.03 \mathrm{~cm}$ for the witness. What made it possible to observe significant differences. The organomineral combination Entada abyssinica $+N P K$ emerged on all the parameters in this study by taking the head of the group. The level of output gave Entada abyssinica $+N P K(2653.33 \mathrm{~kg} / \mathrm{ha})>$ Tithonia diversifolia $+N P K>$ Entada abyssinica > NPK > Tithonia diversifolia > Témoin (466.42 kg/ha).

The application of the biomasses T. diversifolia and E. abyssinica in organomineral combination on a corn culture exploits a multiple role physics, the chemistry and the biology of the ground with like consequence an increase in the output of about $2186,91 \mathrm{~kg}$ of grains compared to the ground untreated. The biomasses used only also gave good results compared to the witness. Considering the difficulties of accessibility to mineral manure, the use of E. abyssinica and T.diversifolia in an environment as this one would contribute to the promotion of the contribution of this organic matter in the majority of the poor grounds.
\end{abstract}

Key words: Tithonia diversifolia, Entada abyssinica, Manure, Corn.

\section{INTRODUCTION}

The problem Sub-Saharan Africa is a zone where the demographic transition is made wait from here 2050, as that world which one projects between 8 and 11 billion inhabitants to be nourished[1].This zone is in the tropical area where the grounds by their nature (acid ground) undergo the degradation of the physicochemical properties because of the aggressive character of the climate of the area; those lose their qualities more and become unfertile[2].In such grounds, the agricultural production is sufficiently weak especially for cereals like the corn (Zea mays L.)to meet the food needs for an unceasingly increasing population[3].The corn among food grains is cultivated in tropical zone, and requires good grounds to have a good output. It's entraining production an impoverishment of the ground especially when management becomes inadequate between exports by corn and stock available in the ground. These two mobiles constitute the principal factor responsible for the fall of the corn yields in field. Generally, agriculture in Africa Subsaharienne is characterized by a low productivity due primarily to the fall of the fertility of the grounds and the difficulties which the peasants meet to answer it[4].The Democratic Republic of Congo (RDC) is a country of the Subsaharienne area where agriculture constitutes the sector which employs more or less $70 \%$ of the population, but the food availabilities are characterized by a shortage for considerable its population. To mitigate this dead end and to primarily make up 
the deficits in production food local of corn, the recourse to the imports of this food product in certain countries like Zambia and South Africa remains one of the palliative solutions, especially for Mbandaka and Kasai where the corn is the component main part of the daily meal[5].So in order to break this dependence of food corn stock in RDC, it will be necessary to increase the national production with technologies innovating in agriculture. However, it was already established[6] that the export of nitrogen $(\mathrm{N})$, Phosphorus $(\mathrm{P})$ and Potassium $(\mathrm{K})$ by the cultures with each harvest and the other types of the losses as the chemical conversions entrainment a negative balance of about $-27 \mathrm{~kg} / \mathrm{ha}$ per year of $\mathrm{N},-4 \mathrm{~kg} / \mathrm{ha}$ per year of $\mathrm{P},-18 \mathrm{~kg} / \mathrm{ha}$ per year of $\mathrm{K}$ It is consequently necessary to exploit the options available to balance these losses. To this end, the uses of artificial fertiliser are put in foreground like plausible alternative in much of the agricultural areas of the world. But certain studies[7] showed that the productivity of the grounds in the Tropics drops even with the use only continues artificial fertilisers. One also raises that the use of the mineral manures which are suitable for increase the productivity of the grounds poses certain problems related to their difficult accessibility, their cost high compared to the income of the Congolais peasants and Kabindais in particular, the degradation of the ecosystems by pollution, even the risk to disturb human health. Moreover, it requires a technical training for their good use[8].There is thus urgency to develop and promote adapted technologies, alternatives which will support the enrichment of the ground. These methods will have to give him a better aptitude to retain water and manures, and to place them easily at the disposal of the plants while avoiding their loss towards the ground water. In short, to improve the physical properties, chemical and biological of the ground by the organic soil conditioners[9]. According[10], the best practice to improve the fertility of ground remains the use of the organic manure. The valorization of the tropical grounds in a durable way to ensure the perenniality and the durability of exploitation of the aforesaid grounds would rest on the biological agriculture which appears to be the suitable solution to play a major role in the promotion and the maintenance of the fertility of the grounds compared to conventional agriculture[11]. The only difficulty is the use of the technique on a large scale of continuation of the unavailability of the organic matter[12]. Although organic manures only are insufficient to compensate for the low level of the nutritive elements in the tropical grounds[13], their beneficial effects on the physicochemical and biological properties of the ground would make it possible to make more effective the use of modest amounts of mineral manures. But the success of this strategy will also depend on the quality of the organic material used and the quantity of nutritive elements contained in this material[13]. There is thus a real need to evaluate the organic soil conditioners based on vegetable species available in the area in order to diversify the options and to reduce the dependence of the peasants with respect to conventional agriculture. From where, this study led to Kabinda during the crop year 2015 B in order to evaluate the effects of organic soil conditioners at base of the leafy biomasses of Tithonia diversifolia, Entada abyssinica and of the artificial fertilizers on the growth and the output of corn.

\section{MATERIALS AND METHODOLOGY}

\subsection{Medium of study}

The town The study was carried out with the site of the teaching higher Institute located at Mbandaka, in the province of Ecuador in Democratic Republic of Congo. The geographical co-ordinates of the site experimental are $039^{\prime}$ E, 1820 ' S and 370 m of altitude. The climate characteristic of the experimental site is of Af type according to the classification of Koppen. It is a tropical climate characterized by the 2 seasons alternation: rainy which lasts 9 months (from August at April), and 3 months a dry season (from May to July).The annual average rainfall reaches $1800 \mathrm{~mm}$, and the average annual temperature oscillates around 25C.The near total of the ground on the site is acid, generally pertaining to the group of ferralsols according to the classification of the INEAC of 1961 (Ministry for the plan, 2005).This light ground, easily drained and washed, with a water holding capacity very low (poor grounds with agricultural low value).

\subsection{Material of studies}

The vegetable material was consisted of the variety of Musangana corn registers with the national catalogue of the varieties approved by the National Service of Seeds[16], of the organic matter of E. abyssinica and T. diversifolia.Manure NPK (17-1717) had been used as mineral fertilizer.

\subsection{Methods}

The test was carried out during the second season of rain 2019-2020.The preparation of the bed of seed was done manually with the hoe of which the depth of ploughing is estimated at $15 \mathrm{~cm}$. The clearing and ploughing took place the 05/01/2020.Two weeks later, we carried out the hiding of the biomasses of two vegetable species like green manures. The application of mineral manure was localised with the foot of each corn seedling while the biomasses used as organic manures were hidden in the furrows of plantation. Sowing took place on January 30, 2020, that is to say ten days after hiding of organic manures. The experimental field was divided into 18 pieces of $5 \mathrm{~m} \mathrm{X} 2.5 \mathrm{~m}$ is $12.5 \mathrm{~m}^{2}$ per experimental unit, separated by alleys from $1.5 \mathrm{~m}$ between the 
repetitions and $1 \mathrm{~m}$ between the treatments. The corn had been sown at a rate of two seeds per seed hole with the spacings of 75 $\mathrm{cm}$ X $50 \mathrm{~cm}$ is 60 seedlings per piece. The care of maintenance consisted primarily with the after-culture of the vacuums six days after sowing, with weeding, the hoeing and the spreading of NPK (17-17-17) 14 days after lifting of the seedlings. The treatments highlighted for the performance evaluation of the amendments are composed of a witness without any contribution, of a contribution of biomass of T. diversifolia, of E. abyssinica with the amount of $8 \mathrm{t} / \mathrm{ha}$ and $250 \mathrm{~kg} / \mathrm{ha}$ of mineral contribution composed of NPK (17-17-17), and an organomineral compound (250 kg NPK+ 8t/ha).This study is installed according to a device in random blocks completion randomized with three repetitions. The parameters of measurements for the experimentation are the variables of growth and production. The variables of growths were observed for one 90 days period with 14 days interval starting from sowing, while the observations of production were evaluated with harvest. These variables are:the diameter with the collet of the seedlings, the height of the plant, the length of ear, the diameter of ear, the number of lines per ear, the weight of 100 grams, the weight of ears with spathes and the weight of ears without spates. Analyze statistical: The collected data were subjected to the analysis of the variance to the threshold of $5 \%$ of probability using software STATISTIX 8.0.The averages were compared a posteriori using the test smaller significant difference (LSD).

\section{RESULTS AND INTERPRETATION}

\subsection{Results}

The results relating to the growth in height of the corn seedlings during the cycle of vegetation are illustrated by figure 1.It is released from the observations that the application of the fertilizing matters in the pieces showed a profit of growth in height throughout all experimentation compared to the witness of the group.Indeed, mineral combination NPK, NPK+ Entada, NPK+ Tithonia;biomasses of T diversifolia, E. abyssinica similarly increased the height of corn during the growth, and of the significant differences were observed compared to the witness $(\mathrm{p}<0.05)$. At the 14 2nd day of growth, the treatment E. abyssinica $+\mathrm{NPK}$ presented seedlings of $23.06 \mathrm{~cm}$ while the lowest value was recorded with the pilot treatment $(11.63 \mathrm{~cm})$. At the $752 \mathrm{nd}$ day, the treatment the E abyssinica +NPK presented seedlings of $180 \mathrm{~cm}$ while the lowest value was recorded with the pilot treatment $(123.33 \mathrm{~cm})$.

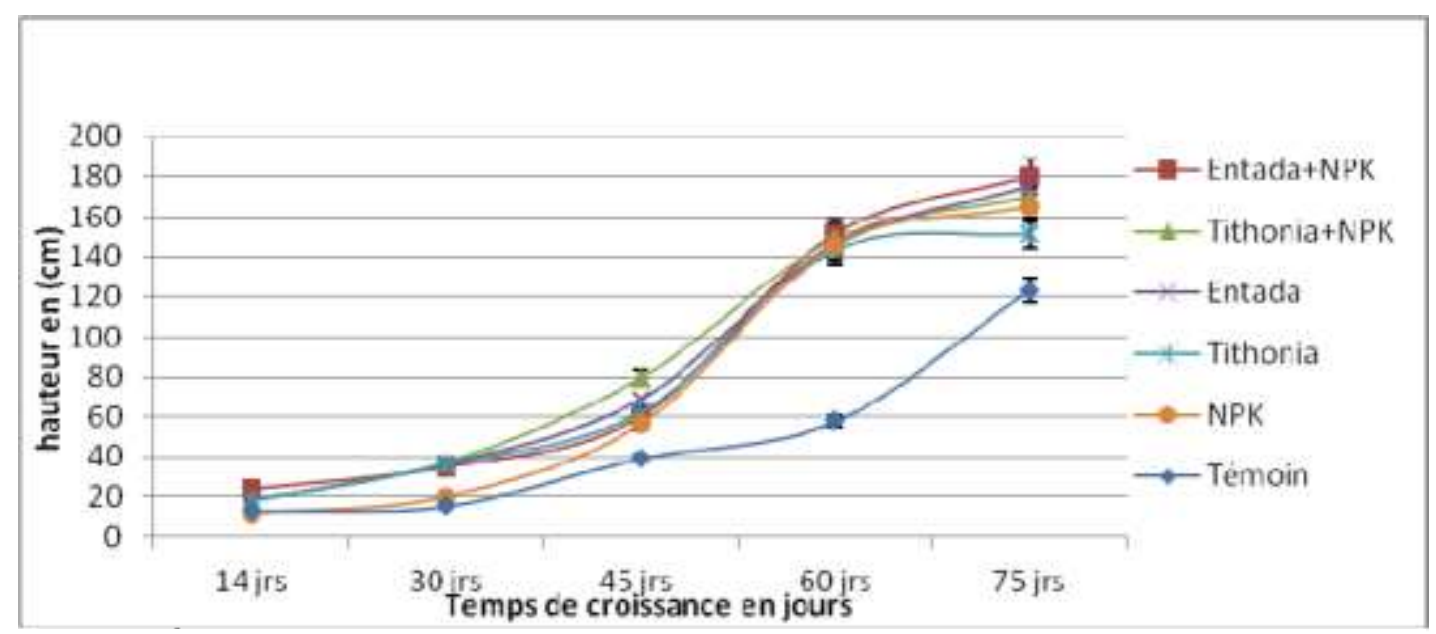

Figure 1: Evolution height of the corn plants in the cycle

Figure-2 which exposes the diameter to the collet of corn from 14 to 75 days of vegetation, one notes that the same pace observed for the height of corn (figure-1) is confirmed once more.To the 14 2nd day of growth, the witness gave $0.53 \mathrm{~cm}$ to the collet compared to the combination E. abyssinica +NPK with $1.33 \mathrm{~cm}$. The witness and mineral combination NPK could not release a significant difference with the threshold of $5 \%$ of probability as for their diameter with the collet.To the 75 2nd day of growth, the witness gave $1.03 \mathrm{~cm}$ while the treatment E abyssinica +NPK gave $2.20 \mathrm{~cm}$ in diameter of seedling to the collet.He is observed that the organomineral combinations (Entada + NPK; Tithonia + NPK) and the organic soil conditioners applied only (Entada, Tithonia) facts in this study released from significant differences $(\mathrm{p}<0.05)$ for this parameter since the beginning of the growth until the end of the observations compared to the witness and the mineral combination of NPK.

The number of the sheets developed during the growth of corn is consigned in the figure-3 below.It appears that the tendency of the curves observed for the diameter with the collet is confirmed once more with regard to the number of the sheets produced during the vegetative growth.At 14 days of growth the witness and mineral combination NPK did not show a significant difference between them ( $p>0.05$ ).But it gets clear that to the 14 2nd and 30 2nd days of growth, the witness and the NPK showed 
statistically significant difference compared to the combination of Entada +NPK;Tithonia +NPK;Entada;Tithonia during the this phase of growth of corn. To the 14 2nd day, the treatment the E abyssinica +NPK gave 7 sheets while the witness had 5 of them. To the 75 2nd day, the treatment the E abyssinica +NPK was noticed with 14 sheets while the witness had 11 of them.

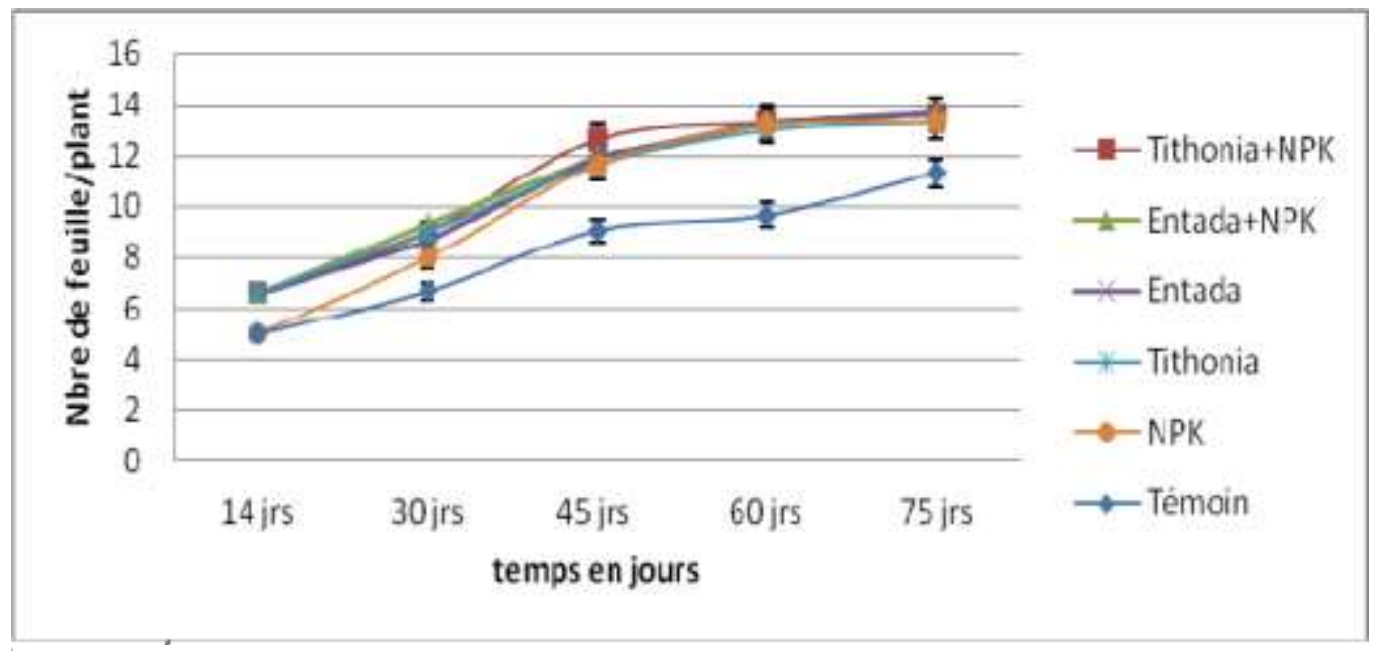

Figure 2: Evolution of the number of sheet per plant

In addition, The parameters of production were observed and measured with the harvest of corn. The parameters taken into account are in particular the length of ear, the diameter in the medium of ear, the number of lines per ear, the weight of 100 grains to $14 \%$ of moisture, the weight of ear with spar and without spar, the extrapolated compartmental output thunders about it per hectare under various fertilizers. These results are presented in the table-1 and figure-4.

Table 1: Average values of the parameters of production of corn

\begin{tabular}{l|c|c|c|c|c|c}
\hline Traitements & $\begin{array}{c}\text { Longueur } \\
\text { épi }(\mathbf{c m})\end{array}$ & $\begin{array}{c}\text { Diamètre } \\
\text { épi }(\mathbf{c m})\end{array}$ & $\begin{array}{c}\text { Nbre } \\
\text { rangés/ épi }\end{array}$ & $\begin{array}{c}\text { Poids de } \\
\mathbf{1 0 0} \text { grains } \\
(\mathbf{g r})\end{array}$ & $\begin{array}{c}\text { Poids épi } \\
\text { avec spath } \\
\text { (gr) }\end{array}$ & $\begin{array}{c}\text { Poids épi } \\
\text { sans spath } \\
\text { (gr) }\end{array}$ \\
\hline Entada+NPK & $14.26 \mathrm{a}$ & $4.16 \mathrm{ab}$ & $14.30 \mathrm{a}$ & $27.70 \mathrm{ab}$ & $152.00 \mathrm{a}$ & $140.33 \mathrm{a}$ \\
\hline Tithonia+NPK & $13.66 \mathrm{ab}$ & $4.10 \mathrm{~b}$ & $14.00 \mathrm{a}$ & $27.00 \mathrm{ab}$ & $146.33 \mathrm{a}$ & $136.00 \mathrm{~b}$ \\
\hline Entada & $12.50 \mathrm{bc}$ & $4.06 \mathrm{~b}$ & $14.00 \mathrm{a}$ & $28.66 \mathrm{ab}$ & $148.33 \mathrm{a}$ & $139.67 \mathrm{a}$ \\
\hline Tithonia & $12.10 \mathrm{c}$ & $4.03 \mathrm{~b}$ & $13.66 \mathrm{a}$ & $27.33 \mathrm{ab}$ & $146.50 \mathrm{a}$ & $124.00 \mathrm{a}$ \\
\hline NPK & $11.90 \mathrm{~d}$ & $4.43 \mathrm{a}$ & $13.66 \mathrm{a}$ & $26.33 \mathrm{~d}$ & $137.03 \mathrm{~b}$ & $127.90 \mathrm{c}$ \\
\hline Témoin & $10.16 \mathrm{~d}$ & $3.90 \mathrm{~b}$ & $13.76 \mathrm{a}$ & $22.22 \mathrm{c}$ & $122.40 \mathrm{c}$ & $114.40 \mathrm{~d}$ \\
\hline CV \% & 6.1 & 4.1 & 2.8 & 4.6 & 1.3 & 3.3 \\
\hline Lsd $(0.05)$ & 1.37 & 0.30 & 0.70 & 2.24 & 3.11 & 6.68 \\
\hline
\end{tabular}

According to the table-1 above, it arises that the length of ears under various treatments put to the test shows significant

differences with the threshold of $5 \%$ of probability according to the analysis of the variance.The shortest ears were observed on the pilot treatment with $10.16 \mathrm{~cm}$ and the longest ears were observed under the application on the ground of Entada +NPK with $14.26 \mathrm{~cm}$.In the same way, the diameter of ears of corn obtained with harvest, according to the statistical test of ANOVA to the threshold of $5 \%$ of probability, the organomineral manure (Entada + NPK; Tithonia + NPK) and organics by the biomasses hidden only (Entada, Tithonia) remain nonsignificant $(\mathrm{p}>0.05)$ then the inorganic manure $(\mathrm{NPK})$ emerges with a diameter $(4.43 \mathrm{~cm})$ significantly different from the other treatments $(\mathrm{p}<0.05)$ of the group in this test and the witness $(3.90 \mathrm{~cm})$. As for the number of lines by ears, it is observed that the various types of manures used do not release any significant difference $(p<0.05)$ between the averages for this parameter.The weight obtained of 100 grains to $14 \%$ of moisture in this study shows that the organic fertilizers and the organomineral combination significantly stimulated $(\mathrm{p}<0.05)$ the weight of the 100 grains. The highest value was obtained with the treatment the E abyssinica (28,66 gr.) and the witness with the lowest value (22.22 gr.).The ear weight with spathe and without spathe summarized in the table-1 shows that Entada+NPK is an elite treatment in the group (152.00 gr. and 140.30 gr.) whereas the weight of the witness is lowest (122.40 gr. and 114.40 gr.).The net yield of corn under the effect of fertilizers brought are consigned in the figure-4.It gets clear that the application of the treatment Entada +NPK gave an output more raised (2653.33 
$\mathrm{kg} / \mathrm{ha}$ ) that other treatments. And the witness gave the output low $(466.42 \mathrm{~kg} / \mathrm{ha})$ But all the treatments rank significantly ( $>0.05)$ above the witness. The contributions of the organic soil conditioners, manure and the organomineral combination seems better to make available the nutritive elements on the ground that on a ground untreated.The mineral supplement played a capital role in theproductivity of the ground enriched by the organic matter.

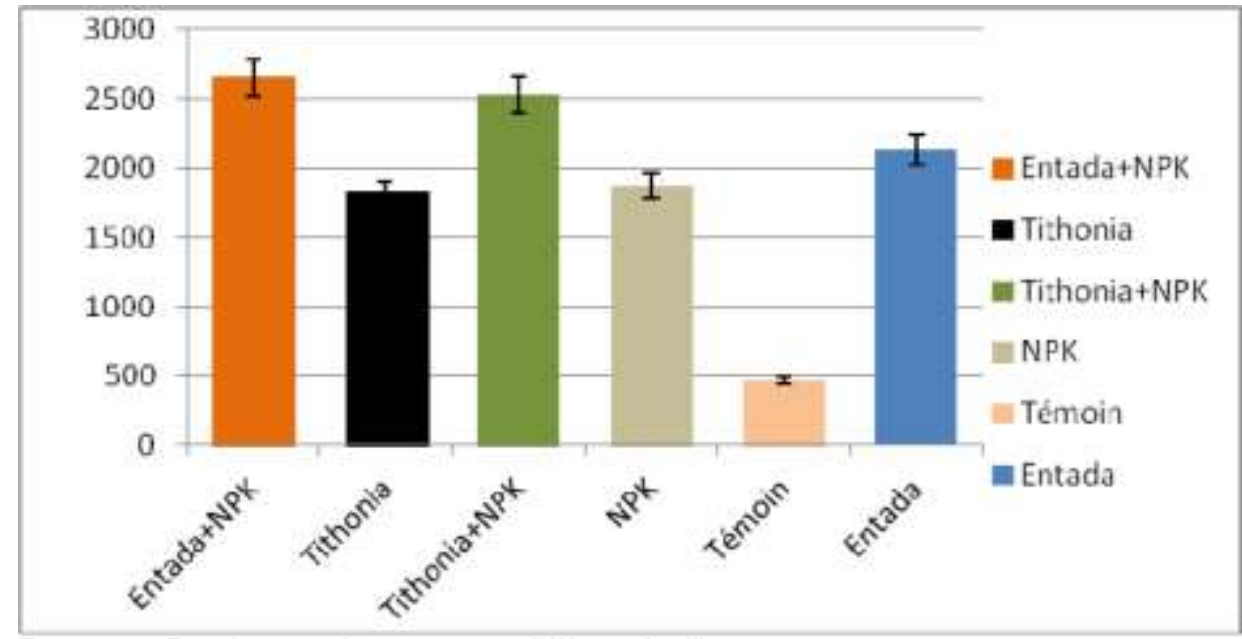

Figure-4 : Rendement de maïs sous différent fertilisant

Figure 4: Corn output under different fertilizer

\subsection{Discussion of the results}

In a general way, the behavior presented by corn under various fertilizers seems to be the function of the contributions. The growth recorded during the experimental period reveals that there are significant differences with the threshold of $5 \%$ of probability.The pieces on which one brought organic fertilizers that mineral had a strong strength of growth in height, in diameter with the collet like in a number of sheets at 60 days of vegetation after sowing, compared to the average of the pilot pieces not having undergoes a soil stabilization. This confirms the disponibilisation of the essential biogenic salts in organic manures for the growth and the development of the cultures in full field as for corn by contributions organomineral.This observation is in agreement with[17].The grounds of the pilot pieces seem to translate the bottom grade of nutritive reserves in the solution of the ground.This could be the major cause of the bad performance of the growth in height of corn observed, so that one did not manage to reach the performances described[16] from 180 to $190 \mathrm{~cm}$.Then, the experimental site being a fallow colonized by I cylindrica and P. maximun, the decomposition of these species rich in cellulose requires, after ploughing, a great energy, but also puts in competition the plants of culture and the micro-organisms of the ground for the nutriments so much so that nitrogen remains mainly immobilized by the micro-organisms[19]. This would more explain the delay of growth observed at corn under study.However the progressive release of the biogenic salts starting from the biomasses of the hidden species would have stimulated up to 60 days of vegetation the growth of corn. This result is in agreement with[20]. It is also added that the application of artificial fertilisers NPK brought only, but also in combination with the biomasses of Entada and Tithonia, would have influenced the growth of corn. Thus our observations also join those of [16]. As for the effects observed in the table-1 referring to the length of ear, the diameter of corn carrots, the number of line under various fertilizers, it is observed significant differences with the threshold of $5 \%$ of probability.The corn under the application of the manures gave carrots having a length, a diameter a number of arranged higher compared to corn exit carrots of the pilot treatment.However the characters length ear, a number of lines per ear and diameter in the medium of carrots would be intrinsic characters of a variety, because[13] had observed that these-known as parameters are not modified by the initial level of fertility of the ground.For them, they allot the phenomenon to an abortion of the grains after flowering.It is especially the reduction of the number of ovules before the anthèse.More the height of ears is not reduced, the number of the grains is also low.The behaviors which emerge from various treatment would be related on the one hand to the intrinsic property of the known as variety and on the other hand to the édapho-climatic environment of the medium of study.Moreover, we note that the average weight of dry corn with and without spathe obtained on the organic treatments only or in combination is significantly different from the other treatments. This confirms the positive interaction of the organic substrates noted already on the level of the growth, like had also noticed it[19]. In comparison with the averages of outputs in corn grains obtained under various fertilizers indistinctly of their nature, it releases a profit significantly perceptible in 
weight that the witness in this study. The positive impact of the manures brought had been also reported by[20]. It is released from the results recorded in this study that the fertilizing matters used in the experimental pieces have a fertilizing potential.One recorded profits of output of about $2186,91 \mathrm{~kg}$ in the combination E abyssinica +NPK moreover than the witness. These results join those obtained by[21] that the application of biomass of $\mathrm{T}$ diversifolia, $\mathrm{E}$ abyssinica only or in combination with an inorganic manure had increased by $1259 \mathrm{~kg}$ and $2942 \mathrm{~kg}$ respectively production of corn with Kabinda and Gandajika

\section{GENERAL CONCLUSION}

Under the conditions of a permanent working pressure of the ground, exports in bioelements are considerable, which induces the loss of fertility of the grounds. To this end, the ground is impoverished more if the measures of corrections are not taken. Thus, such a ground requires that a plan of restitution be applied to maintain and satisfy the potential need for the cultures. The practices of managements of the fertility of the grounds tested in this study indicates that the evolution of the growth and the output obtained on the culture of corn, actually ensured a good vegetative growth and a good output compared to the pieces not having received no amendment (pilot).The organic, organomineral fertilizers like mineral used to improve the properties physics, chemical and biological of the ground gave for this study of the satisfactory results. An increase in the output in grain compared to the ground untreated was obtained. These results constitute an indicator of use of $\mathrm{E}$ abyssinica and $\mathrm{T}$ diversifolia in the environment of study like this one and contribute to the promotion of the contribution of this organic matter in the majority of the poor grounds.

\section{REFERENCES}

1. FREDERIC (2012), Effect of Titonia diversifolia leaves and inorganic fertilizers on maize yield and the properties of a ferratic soil in central Cameroon. Tropiculture 29: 39-45

2. Batiano A, (2006). African soils: Their productivity and profitability of fertilizer use. In Proceedings of the Africain fertilizer summit June 9-13

3. Fao (1999). Agronomic summary of fertilization trials in the Democratic Republic of Congo. CD-ROM, land and water reclamation division Fao viale delle terme de caracalla. Rome

4. Kidinda KL, Kiluba KJ, Tshipama TD, Kilumba KM, Mpoyo MJ, Langunu S, Muteba KM and Nyembo KL (2015) Demonstration of the doses of mineral fertilizers to be applied to new varieties of maize introduced in the Lubumbashi region ( DR Congo). International Journal of Innovation and Applied Studies. 12 (1): 96-103

5. Makala Nzengu P, 2009. Public policy and agricultural management based on harvesting, expropriation and food dependence on imports, ed. CVTK, Kinshasa.32p. Malluohi N, Jutras P, 1986. Improvement of acidic soil degraded by the addition of limestone and organic amendments, and evaluation of the importation of the volume and frequency of additional irrigation on the yield of groundnuts in Sénagale, Agriculture review 43. $\mathrm{N}^{\circ}$ 2. 26-30. Ministry of Planning, 2005. Monograph of Kasaï Oriental, 149p.

6. Ikerra ST, Semu E, Mrema JP, (2007). Combining Tithonia diversifolia and minjingu phosphate rock for improvement of $\mathrm{P}$ availability and maize grain yields on chromic acrisol in Morogoro, Tanzania. In: Bationo A, Waswa B, Kihara J, Kimetu J (Eds). Advances in integrates soil fertility management in Sub-Saharan Africa: Challenges and opportunities, Springer, The Netherlands. 333-344.

7. Ahuja LR, 2003. Quantifying agricultural management effects on soil properties and processes, Geoderma, 116, 1-2.

8. FAO, 2003. International Fertilizer Industry Association, World Phosphate Institute, Fertilizers and their applications, Rabat, 76p. Frédéric A, Valentin B, Jean P and Rene B, 2012.

9. Mokuba W, RV Kizungu, K Lumpungu, (2013). Evaluation of the effect fertilizing of Mucuna utilis L vis-a-vis two amounts of NPK (17-17-17) on the growth and the production of the samaru variety of the corn (Zea mays L) under the optimal conditions. Congo Sciences. 25-32.

10. Lunze L, Kimani PM, Ngatoluwa R, Rabary B, Rachier GO, Ugen MM, Ruganza V, Awadlkarim EE, (2007). Bean improvement for low soil adaptation in Eastern and central Africa. In: Bationo A, Waswa B, Kihara J, Kimetu J (Eds). 
International Journal of Advances in Scientific Research and Engineering (ijasre), Vol 7 (4), April -2021

Advances in integrated soil fertility management in Sub- Saharan Africa: Challenges and opportunities, Springer, The Netherlands, 324-332.

11. Muyayabantu GM, (2010). Management of the cropping system and biological soil fertility for the production of maize in the region of Gandajika. In: Nkongolo KK, Kizungu V, Kalonji-Mbuyi A Agronomic research in country medium for a sustainable food safety in DR Congo. (ISBN 978-0-9867757-0-3), Sudbury, Ontario, Canada, pp. 105-160.

12. Planet J, Pera A, Giovanetti M, (1986). Variations of soil structure and microbial population in compost amended soil. Pant Soil, 106: 113-119

13. Uyo Ybesere EO \& Elemo KA, (2000). Effect of inorganic fertilizer and foliage of Azadirachta and Parkia species on the productivity of early maize, Nigerian Journal of Soil Research, 1, 17-2 INS, 2015. Statistical yearbook 2014, DR Congo. Ministry of Planning and the Revolution of Modernity. National Institute of Statistics. 560p.

14. SENASEN (2007). Varietal catalog of food crops: Cereals (corn, rice), legumes (beans, soybeans, cowpeas), tubers (cassava, sweet potato, potato), Banana tree. Support of the CTB / MINAGRI project, Kinshasa, p153

15. Muyayabantu, GM, Kadiata BD and Nkongolo, KK, (2012). Response of maize to different organic and inorganic fertilization regimes in monocrop and intercrop systems in a sub-Saharan Africa region. Journal of Soil Science and Environmental Management, Vol. 3(2): 42-48.

16. HASSANI AND PERSONS (1994). Application of two organic amendments on soil restoration: Effects on the soil biological properties. Journal Enriron, 35: 1010-1017

17. Mukendi TR and Ngoie KJ, (2015). Effect of organic fertilizers on vegetable production of amaranth (Amaranthus hybridus). Cresa notebooks. 179-193.

18. Mallhoui and Julton (1976). Effect of mineral fertilization on improved varieties of maize under Gagnoa conditions, Ivory Coast, Journal Appli. Biosciences, $\mathrm{n}^{\circ}$ 35, p2235-2243

19. Eden R, (1993). Effect of poultry droppings from channels in Leuceana leucocephala corridors on maize grown on bar land. Agricultural engineer thesis. p73.

20. Nkongolo Mulambuila Michel, Mutombo Tshibamba Jean Michel, Cibanda Mutombo Justin, Muka Mulamba P, Masengu Tshibuyi T, Tshibangu K G, (2016). Contribution to the study of integrated soil fertility management for the cultivation of maize (Zea mays) in the Mbujimayi region, DRC. J. Appl. Biosc. (99): 9416 - 9422. 